\title{
SPEED RUNNER S.A.
}

\author{
Víctor Tateishi Saito* \\ PROFESOR CONTRATADO DE ESAN \\ Área de Operaciones, Métodos Cuantitativos y Sistemas
}

$S$

peed Runner S.A. es una empresa dedicada a la fabricación y comercialización de neumáticos para vehículos automotores. Subsidiaria de la Speed Runner Corporation de Estados Unidos, fue fundada en el Perú en 1943.

Entre 1985 y 1989, cuando las importaciones estuvieron restringidas, esta empresa captaba el $65 \%$ del mercado total, mientras Rubber del Perú, su competidora, abastecía el restante $35 \%$. El producto Speed Runner era preferido por los transportistas, que lo consideraban el más apropiado para las condiciones de trabajo

* Escrito con la supervisión del profesor Armando Valdés Palacio, y sobre la base de la información proporcionada por Elizabeth Arévalo, Arturo Lozano, Eduardo Pancorvo, Luis Solano, Willy Tello y David Zumaeta, alumnos del Programa Avanzado de Marketing de ESAN. No pretende dictar normas de administración logística y distribución, sólo fomentar el intercambio de ideas $\mathrm{y}$ experiencias entre los alumnos. en el país. En todo caso, no había otras alternativas entre las cuales elegir.

Dado que la oferta no abastecía la demanda nacional, la red de distribución obtenía ganancias considerables. Tal era la utilidad que generaba la venta de neumáticos que la mayoría de distribuidores se limitaban a esta única actividad; no aprovechaban la infraestructura de sus establecimientos para brindar servicios colaterales (alineamiento, dirección y balanceo de ruedas) que les generaran ingresos adicionales. Aun así, en este periodo, muchos distribuidores crecieron notoriamente.

En ese entonces, Speed Runner producía alrededor de 20 mil neumáticos mensuales, manejaba una planilla de 750 trabajadores y operaba una planta ubicada en la Carretera Panamericana Norte. Además, contaba con una oficina en Miraflores, distante 15 minutos de la planta, y con dos almacenes de distribución, uno en Trujillo y otro en Arequipa. 


\section{La liberalización del mercado}

A partir de 1990, como consecuencia del cambio de la política económica y de la liberalización del mercado, comenzaron a ingresar al país neumáticos de diversos orígenes y marcas. Speed Runner mantuvo su hegemonía durante los primeros años de la década, pues la calidad de su producto era reconocida como superior. Por entonces, las encuestas realizadas a transportistas respecto de la marca de neumáticos que usaban arrojaban este resultado:

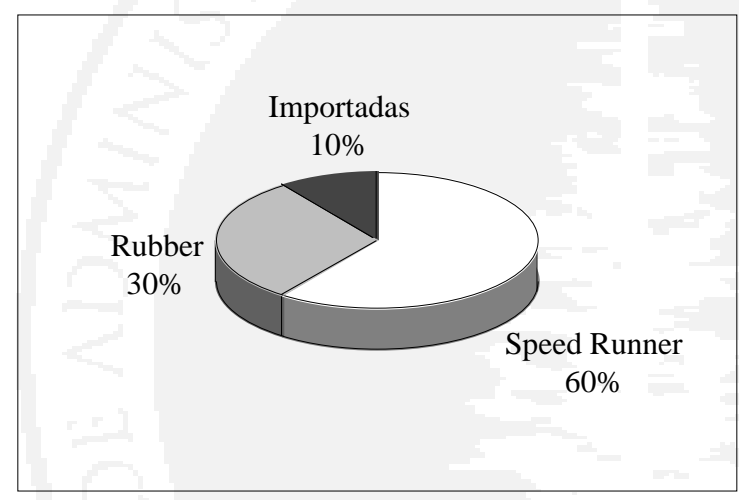

Además, quienes compraban neumáticos importados manifestaban que lo hacían porque eran más baratos.

No obstante, conforme transcurría el tiempo, fue haciéndose evidente que la situación económica no mejoraría; por el contrario, una marcada recesión se impuso hacia 1998 y, en consecuencia, el poder adquisitivo de la población sufrió un serio deterioro. Las personas se vieron forzadas a ajustar sus presupuestos y a comprar artículos más económicos que los que usualmente consumían. Esta situación no fue ajena al sector automotor, y los propietarios de vehículos y transportistas en general dirigieron su atención a la oferta importada.
El nuevo comportamiento de la demanda significó para Speed Runner un drástico decrecimiento de sus ventas $y$, por ende, una sensible disminución de sus utilidades. Fue entonces cuando la empresa comenzó a realizar cambios internos: el personal fue reducido de 750 a 300 trabajadores y se eliminaron los almacenes de provincias, así como la oficina de Miraflores; todos los equipos y materiales fueron trasladados a la planta.

Tiempo después, Speed Runner pudo evaluar los resultados de las decisiones tomadas. Pese a la contracción de la demanda, llegó a fabricar hasta 50 mil neumáticos mensuales, los cuales eran vendidos en su totalidad. Aunque aparentemente paradójico, el incremento de la producción se explica por sí solo, ya que, como consecuencia de la liberalización, también ingresaron al país vehículos automotores de todo tipo y marca, sector que también mostraba un déficit considerable de oferta "barata".

Speed Runner redujo entonces sus costos de fabricación y logró ofrecer al mercado un producto de buena calidad pero con un precio algo superior al de la competencia. Debe mencionarse que la política arancelaria dio margen para reducir los costos de importación de materia prima, mientras las nuevas leyes laborales permitieron ganar eficiencia con menor número de personal.

Hasta ese entonces, el mercado se estructuraba de manera que se podía decir que las llantas importadas estaban ganando terreno (tal como puede verse en la siguiente figura). 


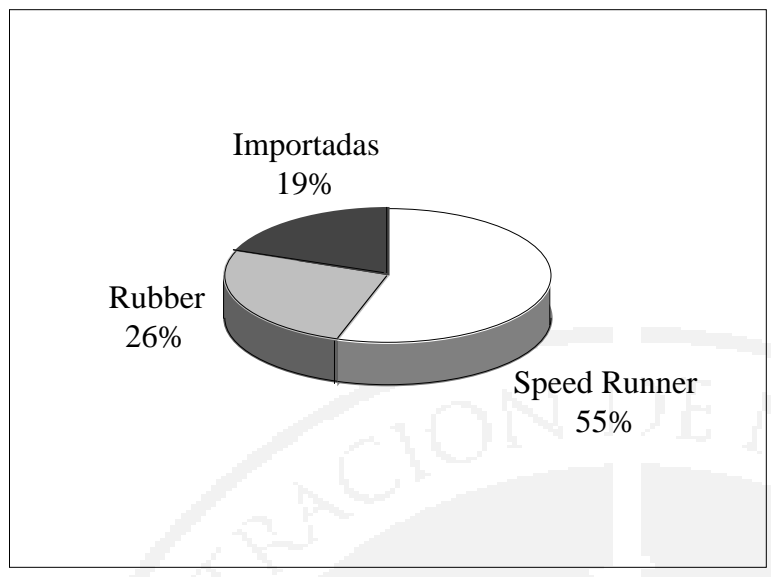

establece sus propios puntos de venta en las diferentes provincias. En el caso de Lima no hay exclusividad alguna; el mercado es atendido por varios distribuidores ubicados en los diferentes distritos de la capital.

Entre los distribuidores de neumáticos Speed Runner se puede distinguir tres categorías. La primera de ellas es la de los distribuidores principales, aquellos que por su antigüedad, dimensión y campo de

El incremento de la producción de 20 mil a 50 mil unidades provocó que la velocidad de rotación de los neumáticos en la empresa y en los establecimientos distribuidores aumentara, pero el margen de utilidad que se solía obtener debió reducirse. El hecho afectó, sobre todo, al negocio de los distribuidores, que debieron invertir más y esforzarse más para poder obtener el mismo monto de ingresos que en la etapa anterior. No sólo debían vender mayor número de neumáticos, también tenían que ofrecer servicios complementarios: enllante, balanceo, alineamiento, suspensión, revisión de frenos, cambio de aceite, etc.

\section{Los distribuidores}

La red de distribuidores de los neumáticos Speed Runner está compuesta por más de 80 puntos de venta repartidos en todo el país, 15 de los cuales son los más importantes, ya que responden por alrededor del $80 \%$ de las ventas. Los territorios, excepto la ciudad de Lima, están divididos en departamentos, en cada uno de los cuales un único distribuidor tiene la representación exclusiva de la marca y acción han invertido fuertes sumas de dinero en el negocio y, por tanto, su volumen de compras es mayor que el de los demás.

Entre estos distribuidores destaca Milop, que concentra el $20 \%$ de las ventas totales de la compañía y cuyo propietario es muy respetado por los otros miembros de la red. Generalmente se tiene en cuenta sus ideas y opiniones; no en vano ha cumplido 40 años como distribuidor.

La segunda categoría corresponde a los denominados "llantaservice", distribuidores cuyos establecimientos cuentan con el personal y las instalaciones necesarias para brindar a los clientes servicios de primera y atención personalizada y cordial que contribuyen a reforzar la imagen de calidad del producto. El volumen de ventas de estos distribuidores es, sin embargo, menor que el de los distribuidores principales.

Finalmente, el tercer tipo de distribuidores son los llamados "centros", aquellos establecimientos, nuevos o antiguos, cuyos propietarios no tuvieron mucho interés en invertir, expandir su negocio y distribuir 
mayores volúmenes del producto. Estos centros no alcanzan a brindar la calidad del servicio que ofrecen los "llantaservice", factor importante para la compañía, pues según las evaluaciones realizadas, el público consumidor se muestra muy satisfecho con la atención recibida en estos establecimientos.

\section{La situación actual}

El ingreso de nuevos miembros a la red ha sido siempre el tema "candente" de todas las discusiones entre la empresa y los distribuidores, ya que éstos perciben que la presencia de nuevos competidores puede ser perjudicial para su negocio.

Respecto a la distribución, Speed Runner mantiene una política de exclusividad que consiste en que sus distribuidores deben vender solamente sus productos. Argumenta para ello que la calidad del neumático Speed Runner es superior a la de los otros productos del mercado.

Sin embargo, la exclusividad en provincias ha perdido vigencia debido, principalmente, a la falta de capacidad financiera de los distribuidores. En algunos casos un departamento ha sido compartido "de común acuerdo" por dos distribuidores diferentes, ya sea por nuevos como por antiguos de otros territorios.

A propósito, la empresa Rubber perdió su red de distribuidores exclusivos cuando al advertir la sensible disminución de su mercado decidió vender sus neumáticos a cualquier cliente, sin distinguir si se trataba de un intermediario o de un consumidor final. Ahora sus distribuidores son multimarca.
De acuerdo con la política de Speed Runner, los descuentos otorgados a los distribuidores sobre los precios de lista son los siguientes:

\begin{tabular}{|c|c|}
\hline Descuento inicial & $20,0 \%$ \\
\hline $\begin{array}{l}\text { Por cumplimiento } \\
\text { de la cuota asignada }\end{array}$ & $7,5 \%$ \\
\hline $\begin{array}{l}\text { Bonificación adicional: } \\
\text { Distribuidor principal } \\
\text { Llantaservice } \\
\text { Centro }\end{array}$ & $\begin{array}{r}10,0 \% \\
6,0 \% \\
3,5 \%\end{array}$ \\
\hline
\end{tabular}

A todos ellos la empresa otorga créditos a 45 días, sin intereses.

En cuanto al producto en sí, la política de la empresa ha sido siempre respetar la calidad, debido a lo cual los procesos de producción y los materiales utilizados pasan por controles de calidad exigentes y estrictos. El principal componente de las llantas es el caucho natural, que es importado y cuyo precio en el mercado internacional se ha elevado últimamente. Este hecho ha incidido negativamente en los costos de producción de la empresa. La variedad de neumáticos que ofrece Speed Runner abarca casi todos los tipos y medidas que utilizan los vehículos que circulan en el país; de esta manera evita depender de uno o varios modelos específicos.

Hacia el año 2000, los niveles de consumo han vuelto a sufrir una severa reducción por la pérdida de capacidad adquisitiva de la población, lo que está afectando considerablemente los ingresos de los distribuidores. Además, los precios de los neumáticos se mantienen prácticamente estables desde hace casi tres años, pues los incrementos han sido poco significativos. 
La recesión no sólo ha ocasionado la reducción de las ventas, sino también la disminución de la capacidad de pago de las empresas, sobre todo de los transportistas formales o grandes. Esto afecta a la red de Speed Runner y les impide cumplir con sus obligaciones.

En la actualidad, el mercado, que incluye todo el parque automotor, se reparte de la siguiente manera:

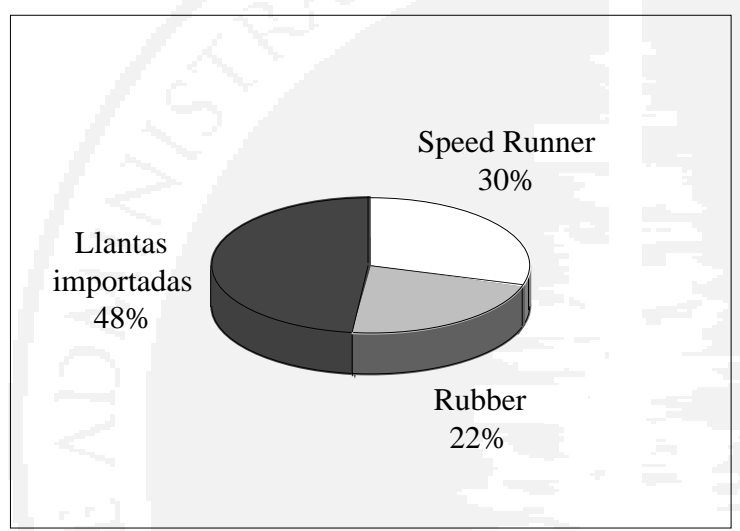

Los márgenes de venta de los distribuidores de llantas importadas son mayores que los que obtienen los distribuidores de Speed Runner, pero su volumen de ventas varía, ya que son pocas las empresas que logran comprar las cantidades mínimas que los fabricantes extranjeros exigen, pues para ello requerirían una gran inversión. Muchos distribuidores prefieren funcionar como minoristas, sin invertir grandes sumas de dinero, pero ello les impide contar con el respaldo y las garantías del caso y no les permite conseguir precios interesantes.

Es por esta razón que, para acceder a precios competitivos y a ventas importantes, los distribuidores de la red Speed
Runner se ven constantemente tentados a vender neumáticos de otras marcas; hecho que sería penalizado por la empresa con el retiro de su condición de distribuidor.

Por otro lado, los minoristas de marcas importadas sí venden neumáticos Speed Runner, ya que normalmente son abastecidos por los distribuidores principales y cuentan con mayor margen de negociación. Los establecimientos de estos minoristas se encuentran ubicados en zonas como La Victoria, donde quedan los terminales de la mayoría de las empresas de transporte que viajan a provincias. Los transportistas buscan menores precios, por encima de cualquier otro factor.

\section{TEMAS PARA DISCUSIÓN}

Usted ha sido nombrado asesor del director de Distribución de Speed Runner S.A.

¿Qué medidas recomendaría para evitarque la red pierda fuerza y se mantenga dentro de las políticas de exclusividad?

¿Qué recomendaría para recobrar la participación de años anteriores en el mercado?

\section{GUÍA PARA EL PROFESOR}

El caso presenta a una empresa productora que pretende mantener sus políticas de distribución y ventas en un contexto de recesión. En este sentido, se presta para el debate y el intercambio de ideas. En medio de la discusión, sería interesante poder diferenciar lo que es una decisión 
de política de lo que es la situación real del mercado.

Conviene tener presente que mientras las políticas dictadas por la empresa estén vigentes deben ser respetadas por todos los miembros y canales de distribución, sin excepción.

El caso no plantea la posibilidad de un cambio de política; busca, más bien, que los lectores propongan alternativas de solución manteniendo la forma como se ha estado operando hasta ahora. Sin em- bargo, se podría discutir qué sucedería si se produjera un cambio diametralmente opuesto con relación a la política actual.

También sería conveniente que se examine el aspecto de bonificaciones, créditos y niveles de precios; esto podría constituir un aporte de los alumnos al caso.

La tercerización también puede ser incluida como tema para el intercambio de ideas y de propuestas entre los alumnos. 